\title{
Rhinovirus: A Narrative Review on Its Genetic Characteristics, Pediatric Clinical Presentations, and Pathogenesis
}

\author{
Etienne Bizot ${ }^{1,2 *}$, Anais Bousquet ${ }^{2}$, Maelle Charpié ${ }^{2}$, Florence Coquelin ${ }^{2}$, \\ Servane Lefevre ${ }^{2}$, Justin Le Lorier ${ }^{2}$, Margaux Patin ${ }^{2}$, Perrine Sée ${ }^{2}$, Eytan Sarfati ${ }^{2}$, \\ Servane Walle ${ }^{2}$, Benoit Visseaux ${ }^{3,4}$ and Romain Basmaci ${ }^{2,4}$ \\ ${ }^{1}$ Department of Microbiology, Robert Debré Hospital, APHP, Paris, France, ${ }^{2}$ Departement of Emergency and Pediatrics, \\ Louis-Mourier Hospital, APHP, Colombes, France, ${ }^{3}$ Department of Virology, Bichat Hospital, APHP, Paris, France, ${ }^{4}$ University \\ of Paris, Inserm, IAME, UMR1137, Paris, France
}

\section{OPEN ACCESS}

Edited by:

Tauqeer Hussain Mallhi, Al Jouf University, Saudi Arabia

Reviewed by: Arturo Solis-Moya

Dr. Carlos Sáenz Herrera National Children's Hospital, Costa Rica Raffaella Nenna, Sapienza University of Rome, Italy Emerson Carraro, State University of Midwest Paraná, Brazil

*Correspondence: Etienne Bizot etienne.bizot@aphp.fr

Specialty section: This article was submitted to Pediatric Infectious Diseases,

a section of the journal

Frontiers in Pediatrics

Received: 17 December 2020 Accepted: 03 February 2021 Published: 22 March 2021

Citation:

Bizot $E$, Bousquet $A$, Charpié $M$ Coquelin F, Lefevre S, Le Lorier J, Patin M, Sée P, Sarfati E, Walle S, Visseaux B and Basmaci R (2021) Rhinovirus: A Narrative Review on Its Genetic Characteristics, Pediatric

Clinical Presentations, and Pathogenesis.

Front. Pediatr. 9:643219. doi: 10.3389/fped.2021.643219
Human rhinoviruses (HRVs) are the leading cause of common colds. With the development of new molecular methods since the 2000s, HRVs have been increasingly involved among severe clinical infections. Recent knowledge of the HRV genetic characteristics has also improved the understanding of their pathogenesis. This narrative review aims to provide a current comprehensive knowledge about this virus in the pediatric community. HRVs represent a main cause of upper and lower respiratory tract infections in children. HRV is the second virus involved in bronchiolitis and pneumonia in children, and HRV bronchiolitis has a higher risk of recurrent wheezing episode or asthma. Some recent findings described HRVs in stools, blood, or cerebrospinal fluid, thanks to new molecular techniques such as polymerase chain reaction (PCR) by detecting HRVs with high sensibility. However, the high rate of asymptomatic carriage and the prolonged excretion in postsymptomatic patients complicate interpretation. No sufficient data exist to avoid antibiotic therapy in pediatric high-risk population with HRV detection. Severe clinical presentations due to HRVs can be more frequent in specific population with chronic pathology or genetic particularity. Inflammatory response is mediated by the nuclear factor (NF)-kappa B pathway and production of interferon (IFN)-beta and IFN-gamma, interleukin 8 (IL8), and IL1b. No specific treatment or antiviral therapy exists, although research is still ongoing. Nowadays, in addition to benign diseases, HRVs are recognized to be involved in some severe clinical presentations. Recent advances in genetic knowledge or specific inflammatory response may lead to specific treatment.

Keywords: rhinovirus, respiratory virus, children, enterovirus, respiratory tract infection

\section{INTRODUCTION}

Discovered in the 1950s, human rhinoviruses (HRVs) are mostly known as the leading cause of the "common cold"; they are ubiquitous, and HRV infections occur year round (1).

With the development of new molecular methods since the 2000s, HRVs have been increasingly involved in more severe clinical infections. Recent knowledge of the HRV genetic characteristics has 
also improved the understanding of their pathogenesis. This led to a large increase in publications in the recent years. In this review, we aimed to provide a comprehensive assessment of the current knowledge on HRV infections.

\section{METHODS}

We performed a narrative review on HRV describing its genetic characteristics, the current diagnostic methods, the most common pediatric clinical manifestations, and their pathogenesis.

A literature search with different free terms related to human rhinovirus in children ( $<18$ years old) was conducted using the PubMed database until March 31, 2019. Search strategy was restricted to articles published in English and French. Potential articles were screened by title and abstract, and if relevant, the full text was assessed.

\section{GENETIC CHARACTERISTICS AND PHYLOGENY}

HRV is a member of the Picornaviridae family including nine genera, six of which are pathogenic for humans: enterovirus, rhinovirus, hepatovirus, parechovirus, cardiovirus, and kobuvirus. $\mathrm{HRV}$ is often classified into three different species, HRV-A, HRV$\mathrm{B}$, and HRV-C (Figure 1). HRV-A and HRV-B were initially described in the early 1990s, whereas HRV-C, discovered in 2003, was included in the International Committee on Taxonomy of Viruses in 2009 (2).

HRVs are non-enveloped viruses measuring $30 \mathrm{~nm}$. The genome is a positive single-stranded RNA (ssRNA) of 7,200 bp. It consists of a single gene encoding 11 proteins. Four proteins (VP1, VP2, VP3, and VP4) make up the viral capsid that encases the ssRNA genome. VP1, VP2, and VP3 proteins account for the virus' antigenic diversity, while VP4 anchors the ssRNA core to the capsid. There are 60 copies of each capsid proteins, giving to the virion an icosahedral structure with a canyon in VP1 that serves as the binding site to cell surface receptors (3).

\section{DIAGNOSTIC METHODS}

\section{Sample Collection}

HRVs are mostly detected within the first 6 days after the symptoms onset (4). In case of upper respiratory tract infections (URTIs), nasopharyngeal swabbing or aspiration appears to be more sensitive than oropharyngeal swabbing (5). In case of lower respiratory tract infections (LRTIs), samples can be obtained by tracheal or bronchial aspiration, broncho-alveolar lavage, or, more rarely, by pulmonary biopsies.

Samples should be sent in a few hours to the laboratory or kept at $+4^{\circ} \mathrm{C}$ in a viral transport medium and sent within a few days.

\section{Molecular Methods}

Viral culture had low sensitivity and a long delay, up to 14 days. In 1988, Gama et al. described the first PCR-based assay able to detect HRV in primary respiratory samples (6). Real-time PCR methods and multiplex PCR (mPCR) have been recently developed and can allow the detection of HRV within $1 \mathrm{~h}$ with a high detection rate. These $\mathrm{MPCR}$ tests are expensive, ranging up to $120 €(140$ USD) for some of them. Most of these assays cannot differentiate enteroviruses and HRVs as targeting the highly conserved 5 ' untranslated region (UTR) region. Thus, during severe central nervous system involvement, more specific tests are required to correctly identify enteroviral infections due to D68, A71, or other enteroviruses $(7,8)$.

\section{Profit-Risk Balance}

Transition to testing with an mPCR led to significantly increased detection of respiratory viruses. Thus, molecular techniques may contribute to de-escalation of antibiotics and reduction in ancillary testing, thereby offsetting the cost of the more expensive PCR test.

However, a first controlled clinical trial using rapid mPCR failed to demonstrate decreased hospital admissions, shorter length of stay, or decreased antimicrobial use for children with acute respiratory infections (9).

Thus, the cost-benefit balance of such test in children populations remains to be determined with the use of appropriate algorithms that still need to be established.

\section{CLINICAL PRESENTATIONS}

\section{Transmission and Epidemiology}

HRV replicates in nasal and posterior nasopharynx mucosa (5). Transmission is mainly attributed to hand contact between persons or through fomites (10). Oral or aerosol transmission seems to be rare and dependent on viral particles concentration in the droplets. Viral loads in saliva are about 30 times lower than in nasal secretions (10).

Morikawa et al. (11), by studying seasonal fluctuations of 16 community respiratory viruses in children both symptomatic and non-symptomatic, demonstrated that HRV-A was present all year round, while HRV-C was more common in winter, and HRV-B had an unclear seasonality.

\section{Common Clinical Presentations}

\section{Asymptomatic Carriage}

Asymptomatic HRV carriage is most often defined as the detection of HRV in nasal sample of children without respiratory symptoms. However, while some authors distinguished asymptomatic from prolonged carriage when children had symptoms during the previous weeks, some others did not search for this information.

It has been estimated to be $14-22 \%(12,13)$, but the methodology was heterogeneous across studies. Thus, HRV asymptomatic carriage is difficult to confirm, as clearance from nasal mucus can occur up to 5 or 6 weeks after the onset of respiratory symptoms in children and can be even longer in case of severe immunosuppression.

\section{Common Cold}

Adults are considered to have an average of 2-5 episodes of common cold per year, while 7-10 episodes per year occur in children (14). Van Beten et al. found HRV in $27 \%$ of common 


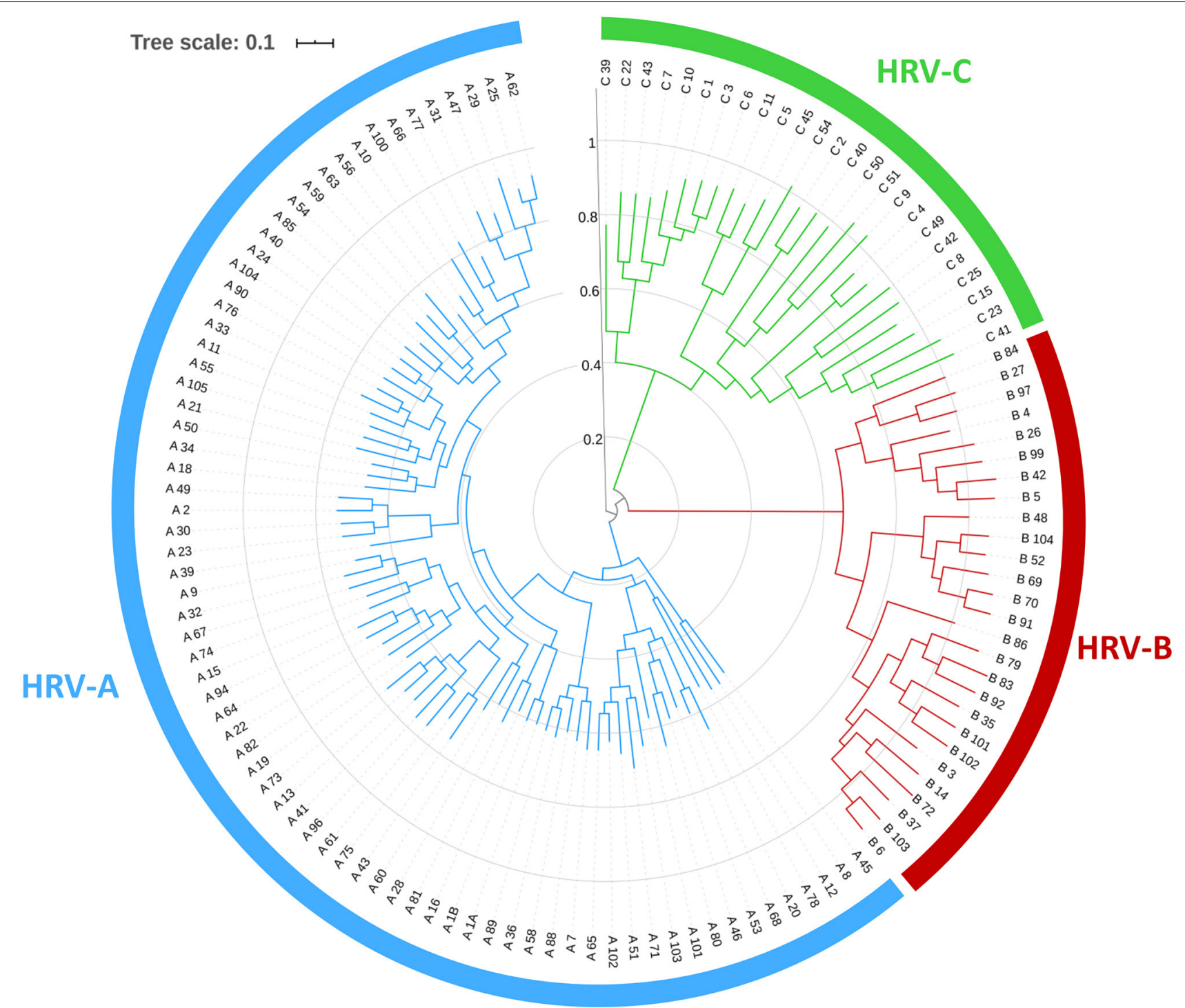

FIGURE 1 | Phylogenetic tree of human rhinoviruses obtained by comparison of near full-length genome using approximated maximum of likelihood with FastTree2.1.

cold episodes in 6-month-old children and 60\% in 24-month-old children (12).

Although it is a benign disease, common cold is associated with significant costs in terms of medical visits, absenteeism, medical prescriptions, and inadequate use of antibiotics (15).

\section{Acute Otitis Media}

Acute otitis media (AOM) are often bacterial or related to bacterial and viral coinfection, but single viral infections may also be involved (16). Among $362<1$-year-old infants who underwent monthly respiratory sampling during 9 months, HRV and respiratory syncytial virus (RSV) were specifically associated with AOM occurrence $(P<0.001)(17)$.

\section{Bronchiolitis}

Bronchiolitis is the main cause of hospitalization in infants. Behind RSV, HRV is the second virus involved in bronchiolitis, accounting for up to $25 \%$ of cases (18).
In different studies, a shorter duration of hospitalization for HRV bronchiolitis was observed compared with RSV (19), while it has not yet been demonstrated whether a specific virus was responsible for more severe infections (20). Moreover, there is no significant difference between the prevalence of RSV and HRV among children hospitalized in pediatric intensive care units and those hospitalized on general pediatric units (21).

However, HRV seems to be more involved than RSV in infants with a high predisposition to atopy due to a higher Th2 immune response (22). Thus, HRV-related bronchiolitis leads to recurrent wheezing episodes after the first bronchiolitis in atopic children (23).

\section{Pneumonia}

In a large study assessing incidence and pathogen distributions of community acquired pneumonia in hospitalized children, viruses (one or more), bacteria, or viral-bacterial coinfections were identified in 66,8 , and $7 \%$ of cases, respectively (24). 
The most commonly detected pathogens were RSV (28\%) and HRV (27\%). All other viruses or bacteria were under $10 \%$. HRV was mostly found among children aged from 5 to 17 years. However, the presence of HRV in the nasopharynx does not necessarily demonstrate its causative role in pneumonia; it can also only indicate a coincidental respiratory infection or prolonged excretion. Moreover, in this study, HRV was detected in $17 \%$ of controls, while any other virus was identified in $<3 \%(24)$.

\section{Asthma}

Viral respiratory infections are the leading cause of asthmatic exacerbation in childhood (25). In 2018, in a large study among 958 children from 1 to 17 years old with moderate to severe asthma exacerbation, $62 \%$ were positive for at least one pathogen, with a large predominance of HRV (29\%) (26).

Children hospitalized with HRV bronchiolitis had a higher risk of recurrent wheezing episode (23) and a higher risk of asthma persistence at 6 years old [odds ratio (OR), 9.8 (4.322.0)] (27) by contributing to the initiation and progression of airway remodeling. However, repeated HRV infections are common in infants, and only few of them developed asthma. Thus, additional risk factors such as host genetic susceptibility and key environmental exposures are also involved in asthma development. Chromosome 17q21 variants (ORMDL3 and GSDMB) have especially been shown to be associated with HRVinduced asthma in children (28).

\section{Specific Clinical Presentations Non-respiratory Infections}

HRV has been also investigated outside the respiratory sphere.

HRV was identified in about $10 \%$ of stool samples of children hospitalized for gastroenteritis (29). In 2015, HRV-C was detected after autopsy in the blood, lungs, stool, and cerebrospinal fluid (CSF) from a healthy 19-month-old patient admitted to intensive care for acute severe respiratory distress (30), highlighting potential circulation of HRV in severe pictures. Such findings still need larger investigations and confirmations in the future.

\section{Infants Younger Than 3 Months Old}

The management of febrile infants younger than 3 months old requires rapid medical assessment, bacteriological sampling, and frequent empirical antibiotic therapy because of frequent bacterial infections (around 10\%).

A study published in 2018 (31) on febrile infants from 1 to 90 days old $(n=4,037)$ detected viral infection in $55 \%$ of cases. Among them, HRV was the most common virus detected (69\%). Children being infected by a respiratory virus were less frequently infected with bacteria (6 vs. 13\%). However, a bacterial infection was more frequently observed in infants with HRV than those with non-HRV viral infection [7.5 vs. 3.5\%, respectively; $\mathrm{RR}=2.12(1.43-3.15)]$. Finally, among infants aged from 1 to 28 days old, urinary tract infection, bloodstream infection, and meningitis were not significantly reduced when HRV was detected. Thus, HRV detection should not discourage antibiotic use on such young children.

\section{Viral Coinfections}

It is common to detect several viruses simultaneously in nasopharyngeal secretions in children. HRV and eight other viruses were searched for in $434>5$-year-old children with respiratory infection symptoms. Among them, 181 (42\%) were HRV positive, $41 \%$ of which had coinfections (32). RSV was the most common virus found concomitantly with HRV. HRV nasopharyngeal aspirates viral load was lower among RSVHRV coinfections compared with HRV monoinfections, but the duration of symptoms was longer in such coinfections than in RSV monoinfections (33). Conflicting results still exist about the causal role of HRV in coinfections, and some studies suggested that HRV inhibits superinfection by other viruses (34).

\section{PATHOGENESIS}

\section{Viral Replication}

In the upper respiratory tract, HRV replication occurs in the nasal mucosa and posterior nasopharynx, mainly in ciliated epithelial cells.

In the lower respiratory tract, HRV can be detected in bronchial biopsy, mainly in columnar epithelial cells, to a lesser extent in the basal cell layer, but also in type II pneumocytes (35).

\section{Binding and Internalization}

After binding to its specific receptor, thanks to canyon in VP1, HRV internalization occurs via clathrin-dependent or clathrinindependent endocytosis or via micropinocytosis (3) (Figure 2).

Intercellular adhesion molecule 1 (ICAM-1) is the epithelial receptor for most HRV-A and HRV-B serotypes, whereas the lowdensity lipoprotein receptor (LDL-R) is recognized by few HRVA. HRV-C uses cadherin-related family 3 (CDHR3) for binding and replication (38).

HRV binding upregulates ICAM-1 expression at the cell surface, allowing multiple ICAM-1 molecules binding by single viral particle. This binding is required to initiate internalization and participates with the low $\mathrm{pH}$ environment in endosomes to the uncoating mechanism of the virions $(39,40)$. Then, HRV pathogen-associated molecular patterns (PAMPs) are recognized by the host cell via interaction with Toll-like receptors (TLRs).

In the endosome, viral recognition by the host pattern recognition receptors (PRRs) will trigger host defenses and induce the production of inflammatory mediators and interferons (41). Adhesion to TLR3 and TLR7/8 leads to the activation of the nuclear factor (NF)-kappa B pathway, triggering production of interferon (IFN)-beta and IFN-gamma, interleukin 8 (IL8), and IL1b leading to antiviral and inflammatory response. Concentration of IL-8 in secretions correlates with the severity of symptoms (42).

\section{Immune Response: T Cells and Antibodies}

HRV antigens are recognized by $\mathrm{T}$ cells, initiating cytotoxic Tcell responses and activating T-helper cells that drive humoral responses. A rapid expansion of epitope-specific memory $\mathrm{T}$ cells occurs after HRV infection allowing T-cell recruitment and facilitating viral clearance (43). 


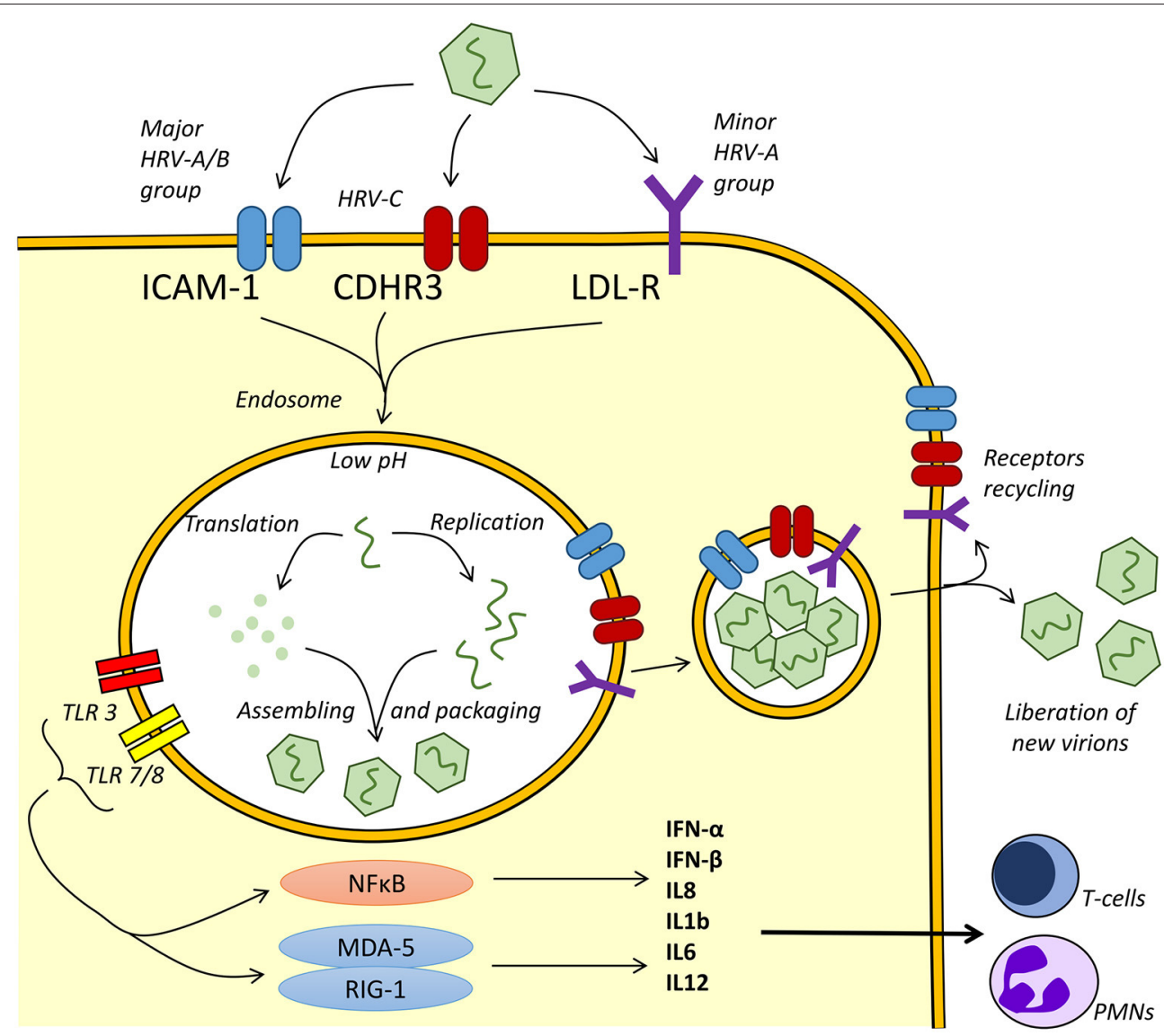

FIGURE 2 | Human rhinoviruse (HRV) replication and inflammatory response. Depending on the serotype, HRVs use intercellular adhesion molecule 1 (ICAM-1), cadherin-related family 3 (CDHR3), or low-density lipoprotein receptor (LDL-R) for endocytosis. After binding, HRV upregulates ICAM-1 and other receptors expression (34). A pH drop leads to viral uncoating after the loss of the capsid protein VP4 and externalization of hydrophobic N-terminal of VP1 (36). In the endosome, viral RNAs are recognized by Toll-like receptor 3 (TLR3) and TLR7/8, while receptors are recycled to apical plasma membrane (37). Nuclear factor (NF)-kappa B pathway and the pattern recognition receptors ([RIG-1] and [MDA-5]) in the intracellular compartment are activated, leading to the production of interleukin 8 (IL8), IL1b, IL6, IL12, and interferon (IFN) beta and gamma. The cascade leads in fine to the increased production of T cells and neutrophil cytokines.

Antibodies produced during HRV infection are serotype specific. This implies the possibility of multiple HRV infections, since more than 100 different serotypes have been described to date (44).

\section{Virulence Factors}

\section{Virus-Related Virulence Factors}

Severity is not related to viral copy number but seems to vary according to the serotype.

Compared to the other groups, HRV-B-related infection is less frequent and severe, causing fewer hospitalizations (45). Regarding HRV-A and HRV-C, conflicting data exist depending on studies and countries $(45,46)$.

\section{Host Factors Related to HRV Infection or Clinical Severity}

- Asthma

Immune response to HRV infection in general population is Th1 mediated. During HRV-driven asthma exacerbations, an amplified Th2 immune response is involved in IL-4, IL-5, and IL-13 productions $(23,47)$.

It was suggested that impaired Th1 responses could lead to poor IFN production and a lack of immune responses during HRV infection, since some authors have described a deficiency in TLR3 and melanoma differentiation-associated protein 5 (MDA5) signaling in children with asthma (48).

\section{- Immunocompromised Patients}

In a study conducted among onco-hematological patients, despite higher viral loads and longer HRV excretion in hematopoietic cells transplants, frequency and severity of HRV infection were similar in pediatric immunocompetent and immunocompromised populations (49) and predisposed to bacterial infection of lower airways in same frequencies as other common viruses (25\%) (50).

Data among non-hematological immunocompromised population are lacking to date.

- Role of MDA-5 Mutation 
MDA-5 and retinoic acid inducible protein I (RIG-I) are intracellular RNA helicases induced by TLR3. They are required for effective innate immune response by their role in IFN $\beta$ expression (51).

Recent studies reported that non-functional MDA-5 leads to recurrent HRV infections and severe presentations $(52,53)$. That deficiency leads to a primary immunodeficiency and causes susceptibility to severe infection only with respiratory viruses as HRV.

\section{Secondary Bacterial Infections}

Temporal correlations between HRV infection and Streptococcus pneumoniae (54) or Kingella kingae (55) have been described. Moreover, HRV infection predisposes to S. pneumoniae infection by overexpression of platelet-activating factor (PAF) receptor and activation of NF-kB increasing $S$. pneumoniae adherence to the airway epithelial cells (54).

In addition, HRV predisposes to Staphylococcus aureus infections by enhancing its internalization into respiratory epithelial cells (56). This effect does not seem to require active viral replication and seemingly involves the release of inflammatory cytokines and the overexpression of ICAM-1.

Finally, HRV can also increase paracellular permeability of airway epithelial cells after infection and even causes the loss of zona occludens 1 from tight junction complexes, disrupting airway epithelial barrier function and contributing to bacterial transmigration across the epithelial barrier and infections (57).

\section{TREATMENT}

To date there is no specific antiviral treatment, and thus, HRV infection management is reduced to supportive care, rest, and hydration. Several decades ago, various antiviral molecules have been tested, but due to the traditionally expected low severity of HRV infection and limited efficiency, none have been commercialized. Zinc or vitamin $\mathrm{C}$ treatments did not prove clinical efficacy (58) despite in vitro effect (59). Steroid did not show any effect by intranasal treatment (60), but, if not showing any impact of development of asthma, systemic steroids seem to reduce recurrence in the year following first hospitalization of HRV bronchiolitis in infants aged 3-35 months (61). Finally, capsid-binding agents (62), protease 3C inhibitor (63), soluble recombinant ICAM-1 (64), and, recently, protein kinase D inhibitors (65) were tested but were not developed further, mostly because of important side effects.

Vaccination against HRV is not effective due to the large number of antigenically distinct serotypes. Nevertheless, some new ways are being explored as the use of complete VP1 protein, which could confer cross-neutralization of HRV strains (66). Thus, to date, HRV infection prevention is reduced to hand hygiene, and no specific isolation is recommended despite the increasingly pointed out HRV impacts.

\section{DISCUSSION}

Although HRV is commonly associated with common cold, the recent development of molecular methods has revealed that HRV is also involved in severe respiratory diseases. These new methods, such as fully automatized mPCR, have increased knowledge about the clinical manifestations of HRV by detecting it in non-respiratory diseases such as gastroenteritis or into cerebrospinal fluid.

However, involvement of HRV in the pathogenesis may be difficult to determinate in certain situations. First, asymptomatic carriage can be detected in children, either several days after a respiratory infection or in healthy children, and this carriage can reach $14-22 \%$ in children $(12,13)$. Second, HRV are often detected with other viruses or bacteria, especially in respiratory diseases (32) or AOM (16). Thus, although respiratory multiplex PCR was presented as an interesting diagnostic tool to reduce antibiotic prescriptions in children, the high detection rate of HRV makes difficult the interpretation of the results. Actually, the detection of HRV in <3-month-old infants (31) or during a severe pneumonia (24) does not allow to avoid antibiotic therapy due to the high risk to miss an associated bacterial infection. The generalization of multiplex PCR in hospitals and community will increase knowledge about HRV epidemiology in children, especially in non-severe presentations.

Recently, pathophysiology of HRV infections has been better investigated, and several new molecular mechanisms have been identified. Thus, some host factors have been identified to explain the ability of HRV to develop severe disease in children, such as the amplified Th2 immune response during asthma exacerbations $(23,47)$ or the role of MDA- 5 deficiency for IFN $\beta$ production $(52,53)$, two essential ways for appropriate immune response. Moreover, although association between bacterial infection and viruses is known for S. aureus (56) or S. pneumoniae (54) for several years, recent data have explored the relation between $K$. kingae and HRV (55) by showing that a temporal relation exists and could be the trigger of $K$. kingae infection, suggesting that HRV infection may facilitate other bacterial infections. In the future, those results should allow describing the inflammatory response to HRV infections, the facilitating role of HRV in some bacterial invasive infections, and potentially identifying new specific immune deficiencies.

To date, neither pharmacological treatments nor vaccine is efficient, and only supportive care are recommended.

However, new treatments are studied in specific population such as HRV-induced asthma. Thus, Omalizumab, an anti-IgE therapy, has shown promising results as a preventive treatment to decrease frequency and severity of HRV exacerbations (67). Preventive treatment is also a clue for HRV control, and many researches are in progress (66). Because no preventive drug treatment exists, non-pharmaceutical interventions (washing hands, social distancing...) are still the better way to decrease the burden of HRV infections in the community (1) and control this neglected, but true, pathogen.

\section{AUTHOR CONTRIBUTIONS}

EB contributed to the acquisition, analysis and interpretation of the data, and drafted the article. AB, MC, FC, SL, JL, MP, PS, ES, and SW collected the data and contributed to the analysis 
and interpretation of data and revised the manuscript critically for important intellectual content. BV contributed to analysis and interpretation of data and revised the manuscript critically for important intellectual content. RB conceptualized and designed the study, contributed to analysis and interpretation of data, and revised the manuscript critically for important intellectual content. All authors final approved the version to be submitted.

\section{REFERENCES}

1. Jacobs SE, Lamson DM, St. George K, Walsh TJ. Human Rhinoviruses. Clin Microbiol Rev. (2013) 26:135-62. doi: 10.1128/CMR.00077-12

2. Carstens EB. Ratification vote on taxonomic proposals to the International Committee on Taxonomy of Viruses (2009). Arch Virol. (2010) 155:13346. doi: 10.1007/s00705-009-0547-x

3. Ledford RM, Patel NR, Demenczuk TM, Watanyar A, Herbertz T, Collett MS, et al. VP1 sequencing of all human rhinovirus serotypes: insights into genus phylogeny and susceptibility to antiviral capsid-binding compounds. J Virol. (2004) 78:3663-74. doi: 10.1128/JVI.78.7.3663-3674.2004

4. Landry ML, Lu X. Rhinoviruses. In: Jorgensen JH, Carroll KC, Funke G, Pfaller MA, Landry ML, Richter SS, Warnock DW, Landry ML, Caliendo AM, Ginocchio CC, Tang Y?W, Valsamakis A, editors. Manual of Clinical Microbiology, 12th ed. Washington, DC: ASM Press (2015). p. 1551-64. doi: 10.1128/9781683670438.MCM.ch91

5. Lieberman D, Lieberman D, Shimoni A, Keren-Naus A, Steinberg $\mathrm{R}$, Shemer-Avni Y. Identification of respiratory viruses in adults: nasopharyngeal versus oropharyngeal sampling. J Clin Microbiol. (2009) 47:3439-43. doi: 10.1128/JCM.00886-09

6. Gama RE, Hughes PJ, Bruce CB, Stanway G. Polymerase chain reaction amplification of rhinovirus nucleic acids from clinical material. Nucleic Acids Res. (1988) 16:9346. doi: 10.1093/nar/16.19.9346

7. Holm-Hansen CC, Midgley SE, Fischer TK. Global emergence of enterovirus D68: a systematic review. Lancet Infect Dis. (2016) 16:e64-75. doi: 10.1016/S1473-3099(15)00543-5

8. Chang P-C, Chen S-C, Chen K-T. The current status of the disease caused by enterovirus 71 infections: epidemiology, pathogenesis, molecular epidemiology, and vaccine development. Int J Environ Res Public Health. (2016) 13:890. doi: 10.3390/ijerph13090890

9. Wishaupt JO, Russcher A, Smeets LC, Versteegh FGA, Hartwig NG. Clinical impact of RT-PCR for pediatric acute respiratory infections: a controlled clinical trial. Pediatrics. (2011) 128:e1113-20. doi: 10.1542/peds.2010-2779

10. D'Alessio DJ, Peterson JA, Dick CR, Dick EC. Transmission of experimental rhinovirus colds in volunteer married couples. J Infect Dis. (1976) 133:2836. doi: 10.1093/infdis/133.1.28

11. Morikawa S, Kohdera U, Hosaka T, Ishii K, Akagawa S, Hiroi S, et al. Seasonal variations of respiratory viruses and etiology of human rhinovirus infection in children. J Clin Virol. (2015) 73:14-9. doi: 10.1016/j.jcv.2015.10.001

12. van Benten I, Koopman L, Niesters B, Hop W, van Middelkoop B, de Waal L, et al. Predominance of rhinovirus in the nose of symptomatic and asymptomatic infants. Pediatr Allergy Immunol Off Publ Eur Soc Pediatr Allergy Immunol. (2003) 14:363-70. doi: 10.1034/j.1399-3038.2003.00064.x

13. van der Zalm MM, van Ewijk BE, Wilbrink B, Uiterwaal CSPM, Wolfs TFW, van der Ent CK. Respiratory pathogens in children with and without respiratory symptoms. J Pediatr. (2009) 154:396-400.e1. doi: 10.1016/j.jpeds.2008.08.036

14. Eccles R. Understanding the symptoms of the common cold and influenza. Lancet Infect Dis. (2005) 5:718-25. doi: 10.1016/S1473-3099(05)70270-X

15. Hellgren J, Cervin A, Nordling S, Bergman A, Cardell LO. Allergic rhinitis and the common cold-high cost to society. Allergy. (2010) 65:77683. doi: 10.1111/j.1398-9995.2009.02269.x

16. Nokso-Koivisto J, Marom $T$, Chonmaitree $T$. Importance of viruses in acute otitis media. Curr Opin Pediatr. (2015) 27:1105. doi: 10.1097/MOP.0000000000000184

17. Chonmaitree T, Alvarez-Fernandez P, Jennings K, Trujillo R, Marom T, Loeffelholz MJ, et al. Symptomatic and asymptomatic respiratory viral infections in the first year of life: association with acute otitis media development. Clin Infect Dis Off Publ Infect Dis Soc Am. (2015) 60:19. doi: $10.1093 / \mathrm{cid} / \mathrm{ciu} 714$
18. Meissner HC. Viral bronchiolitis in children. N Engl J Med. (2016) 374:6272. doi: 10.1056/NEJMra1413456

19. Jartti T, Aakula M, Mansbach JM, Piedra PA, Bergroth E, Koponen P, et al. Hospital length-of-stay is associated with rhinovirus etiology of bronchiolitis. Pediatr Infect Dis J. (2014) 33:829-34. doi: 10.1097/INF.0000000000000313

20. Jartti T, Smits HH, Bønnelykke K, Bircan O, Elenius V, Konradsen JR, et al. Bronchiolitis needs a revisit: Distinguishing between virus entities and their treatments. Allergy. (2019) 74:40-52. doi: 10.1111/all.13624

21. Richard N, Komurian-Pradel F, Javouhey E, Perret M, Rajoharison A, Bagnaud A, et al. The impact of dual viral infection in infants admitted to a pediatric intensive care unit associated with severe bronchiolitis. Pediatr Infect Dis J. (2008) 27:213-7. doi: 10.1097/INF.0b013e31815b4935

22. Nicolai A, Frassanito A, Nenna R, Cangiano G, Petrarca L, Papoff $\mathrm{P}$, et al. Risk Factors for virus-induced acute respiratory tract infections in children younger than 3 years and recurrent wheezing at 36 months follow-up after discharge. Pediatr Infect Dis J. (2017) 36:179-83. doi: 10.1097/INF.0000000000001385

23. Fedele G, Schiavoni I, Nenna R, Pierangeli A, Frassanito A, Leone P, et al. Analysis of the immune response in infants hospitalized with viral bronchiolitis shows different Th1/Th2 profiles associated with respiratory syncytial virus and human rhinovirus. Pediatr Allergy Immunol Off Publ Eur Soc Pediatr Allergy Immunol. (2018) 29:555-7. doi: 10.1111/pai.12919

24. Jain S, Williams DJ, Arnold SR, Ampofo K, Bramley AM, Reed C, et al. Community-acquired pneumonia requiring hospitalization among U.S. children. N Engl J Med. (2015) 372:835-45. doi: 10.1056/NEJMoa1405870

25. Cox DW, Le Soueff PN. Rhinovirus and the developing lung. Paediatr Respir Rev. (2014) 15:268-74. doi: 10.1016/j.prrv.2014.03.002

26. Merckx J, Ducharme FM, Martineau C, Zemek R, Gravel J, Chalut $\mathrm{D}$, et al. Team for the PERC (PERC) D. Respiratory viruses and treatment failure in children with asthma exacerbation. Pediatrics. (2018) 142:e20174105. doi: 10.1542/peds.2017-4105

27. Jackson DJ, Gangnon RE, Evans MD, Roberg KA, Anderson EL, Pappas TE, et al. Wheezing rhinovirus illnesses in early life predict asthma development in high-risk children. Am J Respir Crit Care Med. (2008) 178:667-72. doi: 10.1164/rccm.200802-309OC

28. Çalișkan M, Bochkov YA, Kreiner-Møller E, Bønnelykke K, Stein MM, Du G, et al. Rhinovirus wheezing illness and genetic risk of childhood-onset asthma. N Engl J Med. (2013) 368:1398-407. doi: 10.1056/NEJMoa1211592

29. Harvala H, McIntyre CL, McLeish NJ, Kondracka J, Palmer J, Molyneaux P, et al. High detection frequency and viral loads of human rhinovirus species A to $\mathrm{C}$ in fecal samples; diagnostic and clinical implications. J Med Virol. (2012) 84:536-42. doi: 10.1002/jmv.23203

30. Lupo J, Schuffenecker I, Morel-Baccard C, Bardet J, Payen V, Kaiser L, et al. Disseminated rhinovirus C8 infection with infectious virus in blood and fatal outcome in a child with repeated episodes of bronchiolitis. J Clin Microbiol. (2015) 53:1775-7. doi: 10.1128/JCM.03484-14

31. Blaschke AJ, Korgenski EK, Wilkes J, Presson AP, Thorell EA, Pavia AT, et al. Rhinovirus in febrile infants and risk of bacterial infection. Pediatrics. (2018) 141:e20172384. doi: 10.1542/peds.2017-2384

32. Costa LF, Queiróz DAO, Lopes da Silveira H, Bernardino Neto M, de Paula NT, Oliveira TFMS, et al. Human rhinovirus and disease severity in children. Pediatrics. (2014) 133:e312-21. doi: 10.1542/peds.2013-2216

33. Karppinen S, Toivonen L, Schuez-Havupalo L, Waris M, Peltola V. Interference between respiratory syncytial virus and rhinovirus in respiratory tract infections in children. Clin Microbiol Infect Off Publ Eur Soc Clin Microbiol Infect Dis. (2016) 22:208.e1-6. doi: 10.1016/j.cmi.2015.10.002

34. Greer RM, McErlean P, Arden KE, Faux CE, Nitsche A, Lambert SB, et al. Do rhinoviruses reduce the probability of viral co-detection during acute respiratory tract infections? J Clin Virol Off Publ Pan Am Soc Clin Virol. (2009) 45:10-5. doi: 10.1016/j.jcv.2009.03.008 
35. Kennedy JL, Turner RB, Braciale T, Heymann PW, Borish L. Pathogenesis of rhinovirus infection. Curr Opin Virol. (2012) 2:287-93. doi: 10.1016/j.coviro.2012.03.008

36. Mani B, Baltzer C, Valle N, Almendral JM, Kempf C, Ros C. Low pHdependent endosomal processing of the incoming parvovirus minute virus of mice virion leads to externalization of the VP1 N-terminal sequence (N-VP1), N-VP2 cleavage, and uncoating of the full-length genome. J Virol. (2006) 80:1015-24. doi: 10.1128/JVI.80.2.1015-1024.2006

37. Blaas D, Fuchs R. Mechanism of human rhinovirus infections. Mol Cell Pediatr. (2016) 3:21. doi: 10.1186/s40348-0160049-3

38. Basnet S, Palmenberg AC, Gern JE. Rhinoviruses and their receptors. Chest. (2019) 155:1018-25. doi: 10.1016/j.chest.2018.12.012

39. Chan SCH, Shum DKY, Tipoe GL, Mak JCW, Leung ETM, Ip MSM. Upregulation of ICAM-1 expression in bronchial epithelial cells by airway secretions in bronchiectasis. Respir Med. (2008) 102:287-98. doi: 10.1016/j.rmed.2007.08.013

40. Nurani G, Lindqvist B, Casasnovas JM. Receptor priming of major group human rhinoviruses for uncoating and entry at mild low-pH environments. J Virol. (2003) 77:11985-91. doi: 10.1128/JVI.77.22.11985-11991.2003

41. Kimura H, Yoshizumi M, Ishii H, Oishi K, Ryo A. Cytokine production and signaling pathways in respiratory virus infection. Front Microbiol. (2013) 4:276. doi: 10.3389/fmicb.2013.00276

42. Turner RB, Weingand KW, Yeh CH, Leedy DW. Association between interleukin-8 concentration in nasal secretions and severity of symptoms of experimental rhinovirus colds. Clin Infect Dis Off Publ Infect Dis Soc Am. (1998) 26:840-6. doi: 10.1086/513922

43. Kelly JT, Busse WW. Host immune responses to rhinovirus: mechanisms in asthma. J Allergy Clin Immunol. (2008) 122:67182. doi: 10.1016/j.jaci.2008.08.013

44. Palmenberg AC, Rathe JA, Liggett SB. Analysis of the complete genome sequences of human rhinovirus. J Allergy Clin Immunol. (2010) 125:11909. doi: 10.1016/j.jaci.2010.04.010

45. Iwane MK, Prill MM, Lu X, Miller EK, Edwards KM, Hall CB, et al. Human rhinovirus species associated with hospitalizations for acute respiratory illness in young US children. J Infect Dis. (2011) 204:170210. doi: 10.1093/infdis/jir634

46. Cox DW, Bizzintino J, Ferrari G, Khoo SK, Zhang G, Whelan S, et al. Human rhinovirus species $C$ infection in young children with acute wheeze is associated with increased acute respiratory hospital admissions. Am J Respir Crit Care Med. (2013) 188:1358-64. doi: 10.1164/rccm.201303-0498OC

47. Steinke JW, Borish L. Immune responses in rhinovirusinduced asthma exacerbations. Curr Allergy Asthma Rep. (2016) 16:78. doi: 10.1007/s11882-016-0661-2

48. Makris S, Johnston S. Recent advances in understanding rhinovirus immunity. F1000Res. (2018) 7:F1000. doi: 10.12688/f1000research.15337.1

49. Gerna G, Piralla A, Rovida F, Rognoni V, Marchi A, Locatelli F, et al. Correlation of rhinovirus load in the respiratory tract and clinical symptoms in hospitalized immunocompetent and immunocompromised patients. J Med Virol. (2009) 81:1498-507. doi: 10.1002/jmv.21548

50. Jacobs SE, Lamson DM, Soave R, Guzman BH, Shore TB, Ritchie EK, et al. Clinical and molecular epidemiology of human rhinovirus infections in patients with hematologic malignancy. J Clin Virol Off Publ Pan Am Soc Clin Virol. (2015) 71:51-8. doi: 10.1016/j.jcv.2015.07.309

51. Triantafilou K, Vakakis E, Richer EAJ, Evans GL, Villiers JP, Triantafilou M. Human rhinovirus recognition in non-immune cells is mediated by Toll-like receptors and MDA-5, which trigger a synergetic pro-inflammatory immune response. Virulence. (2011) 2:22-9. doi: 10.4161/viru.2.1.13807

52. Lamborn IT, Jing H, Zhang Y, Drutman SB, Abbott JK, Munir S, et al. Recurrent rhinovirus infections in a child with inherited MDA5 deficiency. J Exp Med. (2017) 214:1949-72. doi: 10.1084/jem.20161759

53. Asgari S, Schlapbach LJ, Anchisi S, Hammer C, Bartha I, Junier T, et al. Severe viral respiratory infections in children with IFIH1 loss-of-function mutations. Proc Natl Acad Sci U S A. (2017) 114:8342-7. doi: 10.1073/pnas.1704259114
54. Peltola V, Heikkinen T, Ruuskanen O, Jartti T, Hovi T, Kilpi, et al. Temporal association between rhinovirus circulation in the community and invasive pneumococcal disease in children. Pediatr Infect Dis J. (2011) 30:45661. doi: 10.1097/INF.0b013e318208ee82

55. Basmaci R, Bonacorsi S, Ilharreborde B, Doit C, Lorrot M, Kahil M, et al. High respiratory virus oropharyngeal carriage rate during Kingella kingae osteoarticular infections in children. Future Microbiol. (2015) 10:914. doi: $10.2217 / \mathrm{fmb} .14 .117$

56. Passariello C, Schippa S, Conti C, Russo P, Poggiali F, Garaci E, et al. Rhinoviruses promote internalisation of Staphylococcus aureus into non-fully permissive cultured pneumocytes. Microbes Infect. (2006) 8:75866. doi: 10.1016/j.micinf.2005.09.013

57. Sajjan U, Wang Q, Zhao Y, Gruenert DC, Hershenson MB. Rhinovirus disrupts the barrier function of polarized airway epithelial cells. Am J Respir Crit Care Med. (2008) 178:1271-81. doi: 10.1164/rccm.200801-136OC

58. Douglas RM, Hemilä H, Chalker E, Treacy B. Vitamin C for preventing and treating the common cold. Cochrane Datab Syst Rev. (2007) CD000980. doi: 10.1002/14651858.CD000980.pub3

59. Eby GA. Therapeutic effectiveness of ionic zinc for common colds. Clin Infect Dis Off Publ Infect Dis Soc Am. (2008) 46:483-4. doi: 10.1086/ 527479

60. Hayward G, Thompson MJ, Perera R, Del Mar CB, Glasziou PP, Heneghan CJ. Corticosteroids for the common cold. Cochrane Database Syst Rev. (2012) CD008116. doi: 10.1002/14651858.CD008116.pub2

61. Lehtinen P, Ruohola A, Vanto $T$, Vuorinen $T$, Ruuskanen $O$, Jartti $T$, Prednisolone reduces recurrent wheezing after a first wheezing episode associated with rhinovirus infection or eczema. J Allergy Clin Immunol. (2007) 119:570-5. doi: 10.1016/j.jaci.2006.11.003

62. Hayden FG, Andries K, Janssen PA. Safety and efficacy of intranasal pirodavir (R77975) in experimental rhinovirus infection. Antimicrob Agents Chemother. (1992) 36:727-32. doi: 10.1128/AAC.36.4.727

63. Hayden FG, Turner RB, Gwaltney JM, Chi-Burris K, Gersten M, Hsyu P, et al. Phase II, randomized, double-blind, placebocontrolled studies of ruprintrivir nasal spray 2-percent suspension for prevention and treatment of experimentally induced rhinovirus colds in healthy volunteers. Antimicrob Agents Chemother. (2003) 47:3907-16. doi: 10.1128/AAC.47.12.3907-3916.2003

64. Turner RB, Wecker MT, Pohl G, Witek TJ, McNally E, St George R, et al. Efficacy of tremacamra, a soluble intercellular adhesion molecule 1, for experimental rhinovirus infection: a randomized clinical trial. JAMA. (1999) 281:1797-804. doi: 10.1001/jama.281.19.1797

65. Guedán A, Swieboda D, Charles M, Toussaint M, Johnston SL, Asfor A, et al. Investigation of the role of protein kinase $\mathrm{D}$ in human rhinovirus replication. J Virol. (2017) 91:e00217-17. doi: 10.1128/JVI.00217-17

66. Edlmayr J, Niespodziana K, Popow-Kraupp T, Krzyzanek V, Focke-Tejk $\mathrm{M}$, Blaas D, et al. Antibodies induced with recombinant VP1 from human rhinovirus exhibit cross-neutralisation. Eur Respir J. (2011) 37:4452. doi: 10.1183/09031936.00149109

67. Esquivel A, Busse WW, Calatroni A, Togias AG, Grindle KG, Bochkov $\mathrm{YA}$, et al. Effects of omalizumab on rhinovirus infections, illnesses, and exacerbations of asthma. Am J Respir Crit Care Med. (2017) 196:98592. doi: 10.1164/rccm.201701-01200C

Conflict of Interest: The authors declare that the research was conducted in the absence of any commercial or financial relationships that could be construed as a potential conflict of interest.

Copyright (C) 2021 Bizot, Bousquet, Charpié, Coquelin, Lefevre, Le Lorier, Patin, Sée, Sarfati, Walle, Visseaux and Basmaci. This is an open-access article distributed under the terms of the Creative Commons Attribution License (CC BY). The use, distribution or reproduction in other forums is permitted, provided the original author(s) and the copyright owner(s) are credited and that the original publication in this journal is cited, in accordance with accepted academic practice. No use, distribution or reproduction is permitted which does not comply with these terms. 